\title{
An fMRI Study of Auditory Orienting and Inhibition of Return in Pediatric Mild Traumatic Brain Injury
}

\author{
Zhen Yang,, Ronald A. Yeo,, Amanda Pena,, Josef M. Ling,, Stefan Klimaj, ${ }^{1,2}$ Richard Campbell, ${ }^{3}$ \\ David Doezema, ${ }^{4}$ and Andrew R. Mayer ${ }^{1,2,5}$
}

\begin{abstract}
Studies in adult mild traumatic brain injury (mTBI) have shown that two key measures of attention, spatial reorienting and inhibition of return (IOR), are impaired during the first few weeks of injury. However, it is currently unknown whether similar deficits exist following pediatric mTBI. The current study used functional magnetic resonance imaging (fMRI) to investigate the effects of semi-acute $\mathrm{mTBI}(<3$ weeks post-injury) on auditory orienting in 14 pediatric mTBI patients (age $13.50 \pm 1.83$ years; education: $6.86 \pm 1.88$ years), and 14 healthy controls (age 13.29 \pm 2.09 years; education: 7.21 \pm 2.08 years), matched for age and years of education. The results indicated that patients with $\mathrm{mTBI}$ showed subtle (i.e., moderate effect sizes) but non-significant deficits on formal neuropsychological testing and during IOR. In contrast, functional imaging results indicated that patients with mTBI demonstrated significantly decreased activation within the bilateral posterior cingulate gyrus, thalamus, basal ganglia, midbrain nuclei, and cerebellum. The spatial topography of hypoactivation was very similar to our previous study in adults, suggesting that subcortical structures may be particularly affected by the initial biomechanical forces in mTBI. Current results also suggest that fMRI may be a more sensitive tool for identifying semi-acute effects of mTBI than the procedures currently used in clinical practice, such as neuropsychological testing and structural scans. fMRI findings could potentially serve as a biomarker for measuring the subtle injury caused by mTBI, and documenting the course of recovery.
\end{abstract}

Key words: auditory orienting; bottom-up; functional magnetic resonance imaging; pediatric; traumatic brain injury

\section{Introduction}

$\mathrm{T}$ RAUMATIC BRAIN INJURY (TBI) is one of the most common causes of acquired disability in the pediatric population, the outcome of which can interfere with subsequent academic achievements, occupational performance, and interpersonal relationships (Keenan and Bratton, 2006). In the United States alone, the rate of TBI-related emergency department visits was over 500 per 100,000 for children less than 17 years of age (Faul et al., 2010), and 75\% of these injuries were classified as mild in nature (Centers for Disease Control and Prevention, 2003). While the majority of mild TBI (mTBI) patients fully recover within the first several months of injury (Babikian and Asarnow, 2009; Satz et al., 1997), a small subset of patients may experience persistent neurocognitive or psychosocial dysfunction for years (Anderson et al., 2001; Babikian et al.,
2011; Catale et al., 2009; Fay et al., 2010; McKinlay et al., 2002,2009,2010; Sterr et al., 2006), or even decades (Daneshvar et al., 2011; Hessen et al., 2007; Klonoff et al., 1993). Thus it is critical to identify neuroimaging and behavioral markers sensitive to $\mathrm{mTBI}$ to better understand recovery, and to prevent potentially long-term adverse outcomes from repeated mTBI.

Attentional dysfunction is one of the most commonly reported cognitive sequelae of pediatric TBI (Allen et al., 2010; Babikian and Asarnow, 2009; Ginstfeldt and Emanuelson, 2010). Behavioral or neuropsychological studies examining the acute and chronic effects of TBI on attention functions have generally compared the deficits among mild, moderate, and severe TBI groups, and not surprisingly, found that severe TBI groups have greater problems on various measures of attention (Catroppa and Anderson, 1999a,2003,2005;

\footnotetext{
${ }^{1}$ The Mind Research Network/Lovelace Biomedical and Environmental Research Institute, Albuquerque, New Mexico.

${ }^{2}$ Department of Psychology, University of New Mexico, Albuquerque, New Mexico.

${ }^{3}$ Department of Psychiatry, ${ }^{4}$ Department of Emergency Medicine, and ${ }^{5}$ Neurology Department, University of New Mexico School of Medicine, Albuquerque, New Mexico.
} 
Catroppa et al., 1999b; Kaufmann et al., 1993). However, the use of mTBI as a control group for more severely injured groups prevents an examination of deficits that are specific to this patient population. Other studies that directly compared attention functioning of mTBI patients with non-injured controls have generally reported null outcomes during both acute (Jaffe et al., 1992) and chronic (Anderson et al., 2005; Babikian et al., 2011; Catroppa et al., 2011; Fay et al., 1994) injury phases (Babikian and Asarnow, 2009; Satz et al., 1997). However, subtle deficits (Catroppa et al., 2007), and adverse outcomes (Catale et al., 2009), have been occasionally reported in specific attention domains. Moreover, the wide heterogeneity in time post-injury in previous studies, coupled with variability in performance across a cohort in different developmental phases, may have hindered the ability to detect the effects of mTBI on cognition.

Therefore, a primary goal of research should be to characterize the neural abnormalities following mTBI during the semi-acute phase of injury and determine how they relate to cognitive abnormalities. These are especially important issues for the pediatric population, as late childhood and adolescence are a critical time for brain development (Giedd et al., 1999; Sowell et al., 2002), and the developing brain has been shown to be more vulnerable to diffuse white matter injury (Adelson and Kochanek, 1998; Levin, 2003). However, clinical imaging techniques such as magnetic resonance imaging (MRI; T1- and T2-weighted images), and computed tomography $(\mathrm{CT})$ are generally insensitive to $\mathrm{mTBI}$, providing little information about the brain regions that may have sustained initial damage (Hughes et al., 2004). In contrast, functional MRI (fMRI) offers great promise for elucidating the potential neural substrates for cognitive disruption, given its capability for measuring dynamic changes in neural functioning (Belanger et al., 2007; McAllister et al., 2006). A better biomarker would potentially be helpful with diagnostic information and guide clinical management of mTBI (e.g., medical interventions and return to play/school decisions; Hamilton and Keller, 2010).

The few fMRI studies examining cognitive function following TBI in children and adolescents have primarily focused on more severely injured patients (Cazalis et al., 2011; Karunanayaka et al., 2007; Kramer et al., 2009,2008; Newsome et al., 2007,2008; Tlustos et al., 2011; Wilde et al., 2011), with only two studies focusing on a well-defined mTBI population (Krivitzky et al., 2011; Talavage et al., 2010). Krivitzky and colleagues (2011) reported no difference in brain activation between children with mTBI and healthy controls (HCs) on a working memory task, but they found hyperactivation in mTBI patients in the posterior cerebellum with the addition of a demand for inhibitory control processes. In contrast, Talavage and colleagues (2010) reported hypoactivation in concussed adolescent football players within the left middle and superior temporal gyri, left middle occipital gyrus, and bilateral cerebellum, during an N-back working memory task. Similarly, adult fMRI studies of semi-acute mTBI have also reported a mixture of both hypoactivation (Mayer et al., 2009; McAllister et al., 1999,2001; Witt et al., 2010), and hyperactivation (McAllister et al., 1999,2001; Slobounov et al., 2010; Smits et al., 2009), during a variety of different cognitive challenges.

One major factor contributing to the inconsistent results may be clinical heterogeneity in time post-injury. The two
fMRI studies on pediatric mTBI were conducted either within the semi-acute phase (Talavage et al., 2010), or with a heterogeneous time interval spanning from 8 to 82 days (Krivitzky et al., 2011), comprising a range in which the majority of patients are expected to recover. As significant individual variation in the time course of recovery exists within the mTBI group (Kirkwood et al., 2008; Lovell et al., 2007; Yeates et al., 2009), this clinical heterogeneity makes uncovering the specific pathology quite difficult and may contribute to the inconsistent results seen in the literature. Thus, fMRI studies based on relatively larger samples of pediatric mTBI patients, all within the semi-acute phase of injury, are needed to characterize the subtle alterations in brain activation seen following mTBI during this critical phase of injury.

The orienting of attention to different locations in space is critical for everyday functioning, and has been shown to be mediated by distributed networks in the prefrontal and parietal cortices, regions which may be impaired as a result of diffuse axonal injury and focal lesions (Cicerone et al., 2006). Covert orienting requires attention to be dynamically shifted in the spatial environment, disengaging from the currently attended location to new spatial coordinates based on information from the environment (Corbetta and Shulman, 2011; Mayer et al., 2007). Behavioral and functional imaging studies in adults have demonstrated that spatial orienting is typically impaired in mTBI during the semi-acute stages of injury (Drew et al., 2007; Halterman et al., 2006; Mayer et al., 2009), and that difficulties with disengagement (i.e., shifting attention from one focused target to another) might account for the majority of the attentional deficits observed in this population (Halterman et al., 2006). However, it is unknown whether these deficits also exist in the pediatric mTBI population, and which neuronal structures are responsible for the cognitive difficulties. In the current study, we used event-related fMRI to examine the neural circuitry underlying spatial orienting in pediatric mTBI patients during the semi-acute phase of injury ( $<3$ weeks). To our knowledge, this is the first study using fMRI to examine the semi-acute effects of mTBI on bottom-up (i.e., exogenous/stimulus-driven) attentional orienting in the pediatric population.

In the current study, participants were asked to press a button to identify the location of a target presented in either the right or left headphone. All targets were preceded by a cue, and a trial was considered valid if the cue and the target occurred in the same headphone. During invalid trials, the target occurred in the opposite headphone to the cue. Valid and invalid trials were presented equally (i.e., 50\% of trials) to evoke bottom-up spatial orienting (Mayer et al., 2007,2009). The stimulus onset asynchrony (SOA) between the cue and target were chosen to examine effects of both facilitation (i.e., faster response times for valid relative to invalid trials), and inhibition of return (IOR; faster response times for invalid relative to valid trials). Attentional disengagement occurs following invalid trials at short SOAs and has been associated with both increased reaction times (invalid > valid), and functional activation within the supplementary motor area, frontal eye fields, inferior parietal lobes, and cerebellum (Arrington et al., 2000; Mayer et al., 2004,2007; Thiel et al., 2004). In contrast, IOR occurs at longer SOAs, and has been associated with an equalization or reversal in functional activation within the frontal and parietal orienting network that parallels response time data (valid > invalid; Lepsien and Pollmann, 2002; Mayer et al., 2007). 
As the maturation of the orienting system has been posited to be completed before the age of 10 years (Brodeur and Enns, 1997; Goldberg et al., 2001; Rueda et al., 2004; Waszak et al., 2010), we hypothesized that the current pediatric mTBI sample would exhibit similar deficits in spatial orienting as those reported in the adult mTBI sample (Mayer et al., 2009). Specifically, we predicted that mTBI patients would exhibit deficits in disengagement and reorienting auditory attention following invalid cues, and accordingly exhibit hypoactivation in the disengagement network at shorter SOAs. At longer SOAs, we predicted that mTBI patients would fail to inhibit attentional allocation to a previously cued spatial location (IOR).

\section{Methods}

\section{Participants}

A total of 16 pediatric patients with mTBI (14 males, 3 females; $13.50 \pm 2.13$ years old; $6.94 \pm 2.18$ years of education), and 16 age- and education-matched HCs (12 males, 4 females; $13.19 \pm 1.97$ years old; $7.06 \pm 1.98$ years of education), were recruited for the current study. All patients with mTBI experienced a closed head injury and were recruited from the emergency departments at local hospitals. Patients were evaluated with both neuropsychological tests (mean days postinjury 15.56 \pm 4.52 ), and brain imaging (mean days post-injury $16.06 \pm 4.82$ ), within 21 days of injury (semi-acute phase of injury; See Supplementary Table S1 at www.liebertpub.com/ neu). The inclusion criteria (American Congress of Rehabilitation Medicine) for the mTBI patients were a Glasgow Coma Scale score (GCS) of 13-15 at the initial assessment, an alteration in mental status at the time of injury, a loss of consciousness (if present) of less than $30 \mathrm{~min}$, and post-traumatic amnesia (if present) that was limited to $24 \mathrm{~h}$. Exclusion criteria for both mTBI and HC samples included a positive history of neurological disease, psychiatric disturbance, prior closed head injuries with more than $5 \mathrm{~min}$ loss of consciousness, learning disorder, attention-deficit/hyperactivity disorder (ADHD), substance abuse, or alcohol abuse. Informed consent was obtained from the participants or their guardians according to institutional guidelines at the University of New Mexico.

\section{Clinical assessment}

All participants completed an age-appropriate neuropsychological battery. All neuropsychological tests were administered and scored according to normative procedures.
Raw test scores were converted to T-scores (mean 50, SD 10) using published age-specific norms. To reduce redundancy among similar neuropsychological measures, composite indices were calculated by averaging T-scores of relevant tests. Composite scores were grouped based on both neuropsychological theory and empirical evidence (i.e., zero-order correlation table) for the following five cognitive domains: attention (Trail Making Test A, Stroop Interference Test [color-word and interference scores]), memory (Wide Range Assessment of Memory and Learning [WRAML] Story Memory immediate recall, short-delay recall, and recognition), processing speed (Wechsler Intelligence Scale for Children, Fourth Edition [WISC-IV] digit symbol coding and symbol search), working memory (WISC-IV digit span and letter-number sequencing), and executive function (Wisconsin Card Sort Test standard version [WCST 128] errors and perseverative errors; Trail Making Test B; and Controlled Oral Word Association test). For all neuropsychological index scores, a higher T-score indicated better performance. In addition, the Wide Range Achievement Test, Fourth Edition (WRAT-IV) Word Reading Test was used to provide an estimate of overall premorbid intellectual functioning. Behavioral and emotional issues were measured by Self-Report of Personality (SRP) and Parent-Rating Scales (PRS) of the Behavior Assessment System for Children, Second Edition (BASC-2; Reynolds and Kamphaus, 2004). The cognitive testing and imaging sessions occurred within 1 week of each other for all participants (mean day difference $0.43 \pm 0.92$ day).

\section{Task procedure}

All participants completed an auditory orienting task (AOT) while undergoing fMRI (Fig. 1). Participants rested supine in the scanner with their head secured by a forehead strap. Additional foam padding was added to limit head motion within the head coil. Presentation software (Neuro Behavioral Systems, Columbus, $\mathrm{OH}$ ) was used for stimulus presentation, recording of response times (RT), and accuracy data, and synchronization of stimulus events with the MRI scanner. A non-ferrous key-press device was positioned directly under the subject's right hand to record responses.

Auditory stimuli were presented with an Avotec Silent Scan 3100 Series System and consisted of monaural tones. The first tone $(2000 \mathrm{~Hz})$ served as a spatial cue that correctly (i.e., valid trials) or incorrectly (i.e., invalid trials) predicted the location of a second target tone $(1000 \mathrm{~Hz})$. Auditory stimuli were presented at the same sound level for all subjects as

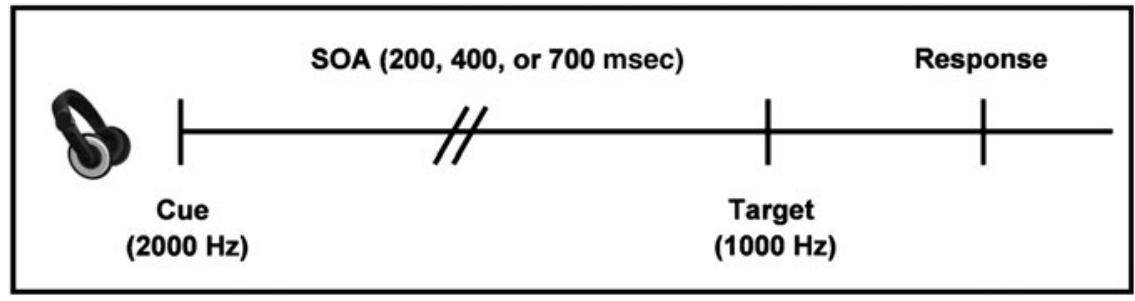

FIG. 1. This figure presents a diagrammatic representation of the auditory orienting task. The headphones were used to present the cue (a 2000-Hz pure tone), and the target (a 1000-Hz pure tone). The stimulus onset asynchrony (SOA) between cues and targets was 200, 400, or $700 \mathrm{msec}$. Cues correctly predicted the target location on half of the trials (50\% validity ratio). Participants responded to the target location by pressing a button with their right index (left target) or middle (right target) finger. 
pre-determined by standard settings. To reduce the occurrence of clicks during auditory stimulus presentation, both tones were sampled with a 10-msec linear onset-offset ramp. To maximize bottom-up orienting effects, participants were informed before the start of the experiment that the cues did not contain any useful information about the target location.

The SOA between the cue and the target was 200, 400, or $700 \mathrm{msec}$, and SOA and cue validity were pseudo-randomly varied throughout the experiment. There were a total of 72 valid ( 24 trials per SOA) and 72 invalid trials presented across three separate imaging runs. The inter-trial interval was pseudo-randomly varied between 4,6 , or 8 sec. These intervals were selected to both facilitate the sampling of the hemodynamic response (Burock et al., 1998), and to minimize the likelihood of non-linear summing of hemodynamic responses (Glover, 1999).

Participants were instructed to respond to the target location by pressing a button with their right middle finger for targets appearing in the right headphone, and right index finger for targets appearing in the left headphone. RT was measured from the onset of the target stimulus to the completion of a key press. RT shorter than $100 \mathrm{msec}$ or longer than $2000 \mathrm{msec}$ were considered anticipatory or missed responses, and were discarded from future analyses. To minimize neuronal activation associated with eye movements, participants were instructed to maintain fixation throughout the task on a white central fixation cross on a black background (visual angle $1.02^{\circ}$ ), which was rear-projected using a Sharp XGC50X LCD projector onto an opaque white acrylic glass projection screen. Participants were required to both practice the tasks and to demonstrate $100 \%$ proficiency before entering the scanner environment.

\section{Functional magnetic resonance imaging}

All images were collected on a 3 Tesla Siemens Trio scanner. High-resolution T1-weighted anatomic images were acquired with a 5-echo multi-echo MPRAGE sequence (echo time $[\mathrm{TE}]=1.64,3.5,5.36,7.22,9.08 \mathrm{msec}$, repetition time $[\mathrm{TR}]=2.53 \mathrm{sec}$, inversion time $[\mathrm{T} 1]=1.2 \mathrm{sec}, 7^{\circ}$ flip angle, number of excitations $[\mathrm{NEX}]=1$, slice thickness $=1 \mathrm{~mm}$, field of view $[\mathrm{FOV}]=256 \times 256 \mathrm{~mm}$, voxel resolution $=1 \times 1 \times 1 \mathrm{~mm}^{3}$ ). T2-weighted images were collected with a turbo spin echo sequence $\left(\mathrm{TE}=77.0 \mathrm{msec}, \mathrm{TR}=1.55 \mathrm{sec}\right.$, flip angle $152^{\circ}$, $\mathrm{NEX}=1$, slice thickness $=1.5 \mathrm{~mm}, \mathrm{FOV}=220 \times 220 \mathrm{~mm}$, matrix $=192 \times 192$, voxel size $=1.15 \times 1.15 \times 1.5 \mathrm{~mm}^{3}$ ). Susceptibility weighted images were collected with a gradient echo sequence $\left(\mathrm{TR}=28 \mathrm{msec}, \mathrm{TE}=20 \mathrm{msec}\right.$, flip angle $15^{\circ}$, bandwidth $=120 \mathrm{~Hz} / \mathrm{Px}, \mathrm{FOV}=180 \times 240 \mathrm{~mm}$, matrix $=177 \times 256$, slice thickness $=1.5 \mathrm{~mm}$, number of slices per slab $=88$ ). Functional images were collected using a single-shot, gradient-echo echo planar pulse sequence $(\mathrm{TR}=2000 \mathrm{msec}, \mathrm{TE}=29 \mathrm{msec}$, flip angle $=75^{\circ}, \mathrm{FOV}=240 \mathrm{~mm}$, matrix size $=64 \times 64$ ), with a total of 148 images per run for 3 runs. The first image of each run was eliminated due to T1 equilibrium effects, leaving a total of 441 images for the final analyses. The whole-brain volume was covered by 33 sequential axial 3.5-mm-thick slices with a gap factor of $1.05 \mathrm{~mm}$ (voxel size $3.75 \times 3.75 \times 4.55 \mathrm{~mm}$ ).

\section{Imaging processing and statistical analysis}

Functional imaging data were processed and analyzed using the Analysis of Functional NeuroImages (AFNI) soft- ware package (Cox, 1996). Time series data were spatially registered to the second echo-planar image of the first run in two- and three-dimensional space to reduce the effects of motion, temporally interpolated to correct for slice time acquisition differences, and de-spiked. These images were then converted to a standard stereotaxic coordinate space (Talairach and Tournoux, 1988), re-sampled to $3 \mathrm{~mm}^{3}$, and blurred using a 6-mm gaussian full-width half-maximum filter.

Deconvolution was performed on a voxel-wise basis, resulting in a hemodynamic response function (HRF) that spanned the first $16 \mathrm{sec}$ post-stimulus onset for each condition (valid and invalid trials at each SOA). To minimize the effect of head motion, six rigid-body motion parameters were entered as noise regressors. The HRF was then normalized by the baseline and re-sampled to $1 \mathrm{~mm}^{3}$. The third and the fourth images (4.0-8.0 sec post-stimulus onset) corresponding to the peak of the HRF were averaged to obtain an estimate of percent signal change.

A voxel-wise, $2 \times 2 \times 3($ group $\times$ validity $\times \mathrm{SOA})$ mixed-design analysis of variance (ANOVA) was then performed on the percent signal change data. For all voxel-wise analyses, multiple comparisons were corrected $(p<0.05)$ based on gaussian random field theory as implemented in the FSL package $(z>2.3)$.

\section{Results}

The data of one HC was compromised secondary to an issue with hearing acuity in the left ear. One mTBI patient was an outlier on behavioral performance (accuracy below chance levels) and was therefore excluded from the study. Additionally, one HC and one mTBI were outliers (greater than three inter-quartile ranges) relative to their cohort on several fMRI motion parameters. Both participants were eliminated from subsequent analyses, leaving data from a total of $14 \mathrm{HC}$ and $14 \mathrm{mTBI}$ patients for final analyses. There were no significant differences between groups on any of the major demographic variables, including age, self-education, parent education, and number of siblings (all $p>0.10$ ), or for hand preference as determined through a self-report measure $(p>0.10)$. There was a marginally significant group difference in gender $[\chi(1)=3.36, n=28 p=0.07]$, with the mTBI group having a higher proportion of males than the $\mathrm{HC}$ group.

\section{Neuropsychological measures}

The results of neuropsychological testing are presented in Table 1. Independent samples $t$-tests indicated that there were no significant $(p>0.10)$ group differences in estimates of premorbid levels of intelligence (WRAT-IV). The composite indices of attention, memory, working memory, processing speed, and executive functioning, were correlated to varying degrees ( $\mathrm{r}^{\prime}$ s ranged from 0.12 to 0.47 ). A multivariate ANOVA (MANOVA) was performed to examine group differences in the cognitive scores. The multivariate effect of group was not significant $(p>0.10)$, although univariate effects indicated trends in the domains of memory $\left[\mathrm{F}_{(1,26)}=3.36, p=0.08\right.$; $\mathrm{HC}>\mathrm{TBI} ; \mathrm{d}=-0.69]$, and processing speed $\left[\mathrm{F}_{(1,26)}=3.48\right.$, $p=0.07 ; \mathrm{HC}>\mathrm{TBI} ; \mathrm{d}=-0.70]$. Moreover, effect sizes in the domains of processing speed, memory, and attention were moderate, suggesting that these results may become significant with minimally increased sample size. 
Table 1. Differences in Demographic Characteristics and Neuropsychological Test Scores between Mild Traumatic Brain Injury (mTBI) and Healthy Control (HC) Participants

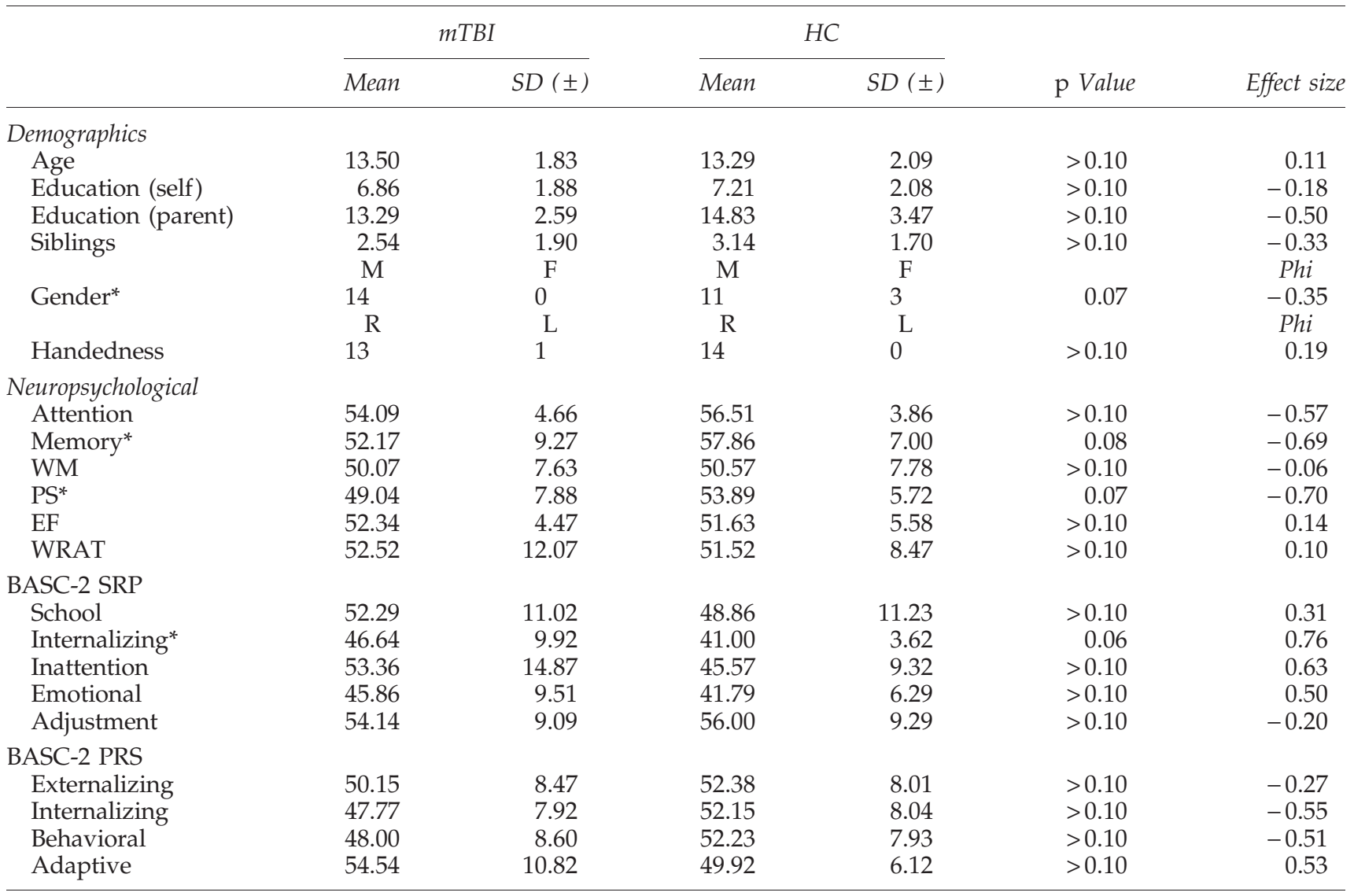

*Denotes a non-significant trend.

Demographic data are raw scores, whereas neuropsychological measures and BASC-2 measures are T-scores. Effect size is equal to Cohen's $\mathrm{d}$ except when otherwise indicated as Phi.

M, male; F, female; R, right; L, left; WM, working memory; PS, processing speed; EF, executive function; WRAT, Wide Range Achievement Test; BASC-2, Behavior Assessment System for Children, Second Edition; SRP, Self-Report of Personality; PRS, Parent-Rating Scales.

Two MANOVAs were performed to examine group differences in the composite scores on the Self-Report Personality and Parent-Rating Scales, separately. The multivariate effects of group were not significant for both MANOVAs (all $p>0.10)$, although there was a trend toward mTBI $(46.64 \pm$ 9.92) reporting more internalizing problems $\left[\mathrm{F}_{(1,26)}=4.00\right.$, $p=0.06 ; \mathrm{d}=0.76]$ relative to $\mathrm{HC}(41.00 \pm 3.62)$.

\section{Behavioral data}

Behavioral accuracy for both the mTBI and HC groups was very high and approached ceiling levels (mTBI: 95.9\% $\pm 5.3 \%$; HC: $94.0 \% \pm 7.4 \%$ ), suggesting that participants had little difficulty distinguishing cues from targets. As a result of low variability across participants, accuracy data was not subjected to further analyses.

Individual participants' median RT for correct trials was used for all behavioral analyses. A $2 \times 2 \times 3$ mixed-measures ANOVA with group (mTBI or HC) as between-subjects factor, and cue validity (valid or invalid) and SOA $(200,400$, or 700 $\mathrm{msec}$ ) as within-subjects factors, was conducted. There was a significant main effect of SOA $\left[\mathrm{F}_{(1,26)}=13.46, p=0.001\right]$, with significantly faster RT at the $700 \mathrm{msec}(566.8 \pm 39.3 \mathrm{msec})$ relative to the $400 \mathrm{msec}(598.2 \pm 44.7 \mathrm{msec})$ SOA [ $\mathrm{t}(27)=-2.9$, $p<0.01$ ], as well as for the $400 \mathrm{msec}$ relative to the $200 \mathrm{msec}$
(704.0 $\pm 42.3 \mathrm{msec})$ SOA [ $\mathrm{t}(27)=-9.3, p<0.001$; Fig. $2 \mathrm{~A}$ and B]. No other main effects or interaction effects were significant $(p>0.10)$.

To examine our a priori predictions of increased costs (200 msec SOA) and reduced IOR (700 msec SOA) across different groups, independent samples $t$-tests were conducted on the validity effect scores (invalid - valid RT). The results indicated that there was no difference between groups at both SOAs (all $p>0.10$ ), which may have been a result of limited power, as the effect size related to the group difference in IOR was medium $(\mathrm{d}=0.62)$. Specifically, follow-up one-sample $t$-tests indicated that the magnitude of IOR was significantly different from zero for HC $[\mathrm{t}(13)=-2.9, p=0.01]$, but not for mTBI patients ( $p>0.10$; Fig. 2C).

\section{Correlations between behavioral data and neuropsychological assessment}

To examine whether the relationship between simple behavioral measure (AOT) and cognitive testing differs between the two groups, correlations between validity effect scores and cognitive composite scores were computed separately for the $\mathrm{mTBI}$ and $\mathrm{HC}$ groups. The validity effect score at $700 \mathrm{msec}$ SOA predicted the attention composite score for HC $(r=-0.63$, $n=14, p=0.02$, uncorrected, with a larger IOR being associated 

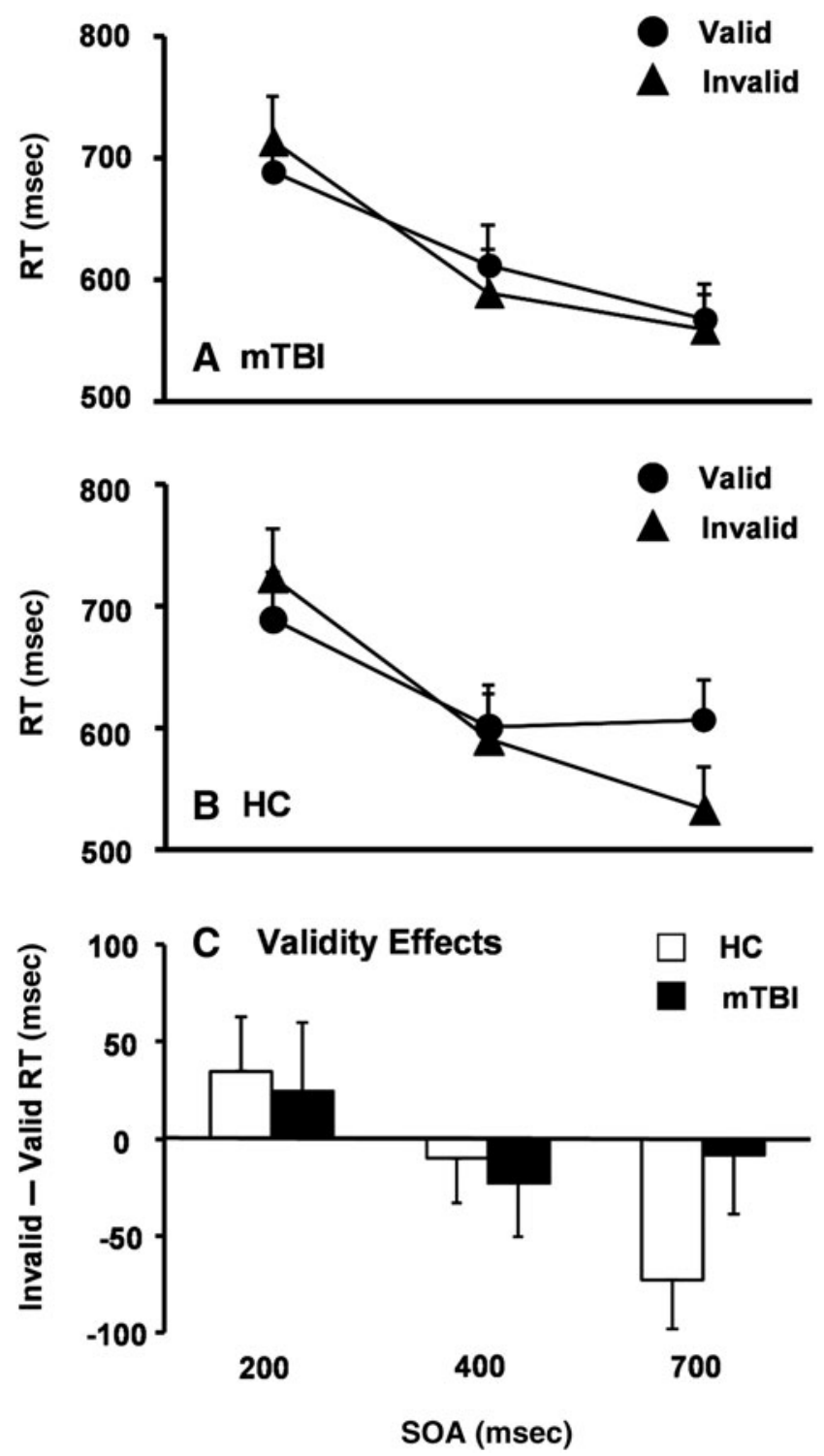

FIG. 2. Graphs A and B show the response time (RT) in milliseconds (msec) for patients with mild traumatic brain injury (mTBI, A), and healthy controls ( $\mathrm{HC}, \mathbf{B})$. In both panels, RT for valid (solid circles) and invalid (solid triangles) trials were plotted as a function of the stimulus onset asynchronies (SOA). Graph $\mathrm{C}$ depicts the validity effect score (RT: invalid - valid trials) for HC (white bars) and mTBI patients (black bars) at each SOA. Error bars correspond to the standard error of the mean.

with better attention function), but not for mTBI patients $(p>0.10)$.

\section{Structural imaging data}

All mTBI patients were found to be non-complicated, that is, free of trauma-related pathology on conventional imaging. Specifically, 10 of 14 mTBI patients had a CT scan at the time of their emergency department visit, which were all deemed to be negative by a board-certified neuroradiologist. In addition, T1-weighted, T2-weighted, and susceptibility-weighted images (SWI) were also acquired for all participants (mTBI patients and $\mathrm{HC}$ ), and reviewed by a neuroradiologist who was blind to study group. All images were deemed to be free of trauma-related pathology.

\section{Functional imaging data}

Two MANOVAs were first conducted to investigate any potential group differences in head motion (both rotational and translational displacements in image space), which could confound our interpretation of the fMRI data. However, the results indicated that the multivariate effect of group was not significant $(p>0.10)$ for either of the MANOVAs, and the effect sizes were small for all six parameters (range from -0.23 to 0.49 ).

Similarly to the behavioral data, a $2 \times 2 \times 3$ mixed-measures ANOVA (group $\times$ validity $\times \mathrm{SOA}$ ) was conducted on the percent signal change data of each trial type. A significant main effect of group was observed within several clusters (Fig. 3 and Table 2), including bilateral posterior cingulate gyrus (Brodmann area [BA] 23); bilateral medial dorsal, ventral anterior, and ventral lateral nuclei of the thalamus; basal ganglia (including bilateral caudate and left putamen/ globus pallidus); bilateral substantia nigra; bilateral subthalamic nucleus; left red nucleus; right pons; and bilateral cerebellar (lingual and culmen). For all regions, mTBI patients exhibited decreased activation (i.e., hypoactivation) relative to the HC group.

Several regions exhibited a significant validity $\times \mathrm{SOA}$ interaction (Fig. 4 and Table 3). These areas included the bilateral pre-supplementary/supplementary motor area and cingulate gyrus (BAs 6/8/24/32), the left precentral and middle frontal gyrus (BA 6), corresponding to the area near the frontal eye fields, the left pre- and postcentral gyrus and inferior parietal lobe (BAs $2 / 3 / 4 / 5 / 7 / 40)$, and the bilateral precuneus, cuneus, and superior parietal lobe (BAs 5/7/18/ 19/31). Simple effects testing indicated increased activation for invalidly-cued over validly-cued trials at $200 \mathrm{msec}$ SOA, followed by a reversal in this pattern at $400 \mathrm{msec}$ SOA. There were no differences in activation in these regions at the 700 msec SOA. In addition, several clusters also demonstrated a main effect of SOA that were not implicated in the SOA $x$ validity interaction, which could generally be characterized by three different patterns of activation: shorter SOA dominance, crossing SOA dominance, and longer SOA dominance. A complete description of these findings can be found in the supplementary material (See Supplementary Table S2 at www.liebertpub.com/neu).

Finally, we examined the ability of functional activation within the bilateral posterior cingulate gyrus, thalamus/basal ganglia, and cerebellum, to classify mTBI and individual HC using binary logistical regression. The results indicated that functional data were able to accurately classify 12/14 HC and $12 / 14$ mTBI patients (overall $85.7 \%$ accuracy). However, none of the Wald statistics were significant $(p>0.10)$, suggesting that none of the regions contributed unique variance to the overall accuracy rate.

\section{Discussion}

The orienting of attention to different locations in space is critical for everyday functioning (e.g., crossing the street), and deficits in spatial orienting have been reported in the adult mTBI population during the first few weeks post-injury 

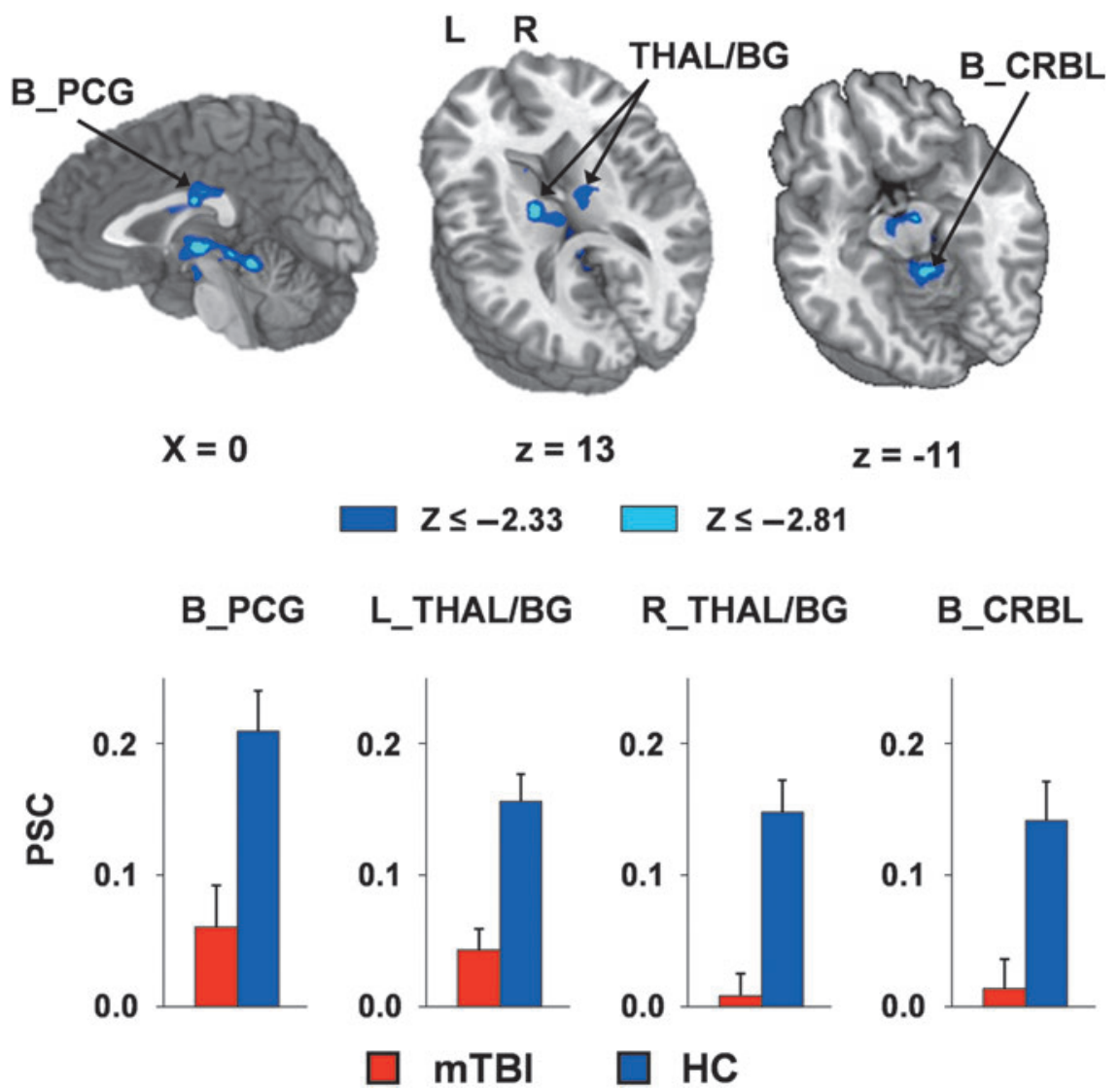

FIG. 3. This figure presents regions showing significant group differences across all task conditions, and the percent signal change (PSC) values for mild traumatic brain injury (mTBI, red bars), and healthy controls (HC, blue bars). The magnitudes of $\mathrm{z}$-scores are represented by either blue or cyan coloring. Locations of the sagittal $(\mathrm{X})$ and axial $(\mathrm{Z})$ slices are given according to the Talairach atlas (L, left; $\mathrm{R}$, right). Decreased activation for mTBI patients compared to HC was observed within the bilateral posterior cingulate gyrus (B_PCG), the left and right thalamus and basal ganglia (THAL/BG), and bilateral cerebellum (B_CRBL). Error bars correspond to the standard error of the mean.

(Drew et al., 2007; Halterman et al., 2006; Mayer et al., 2009). Our current behavioral results indicated that pediatric mTBI patients showed subtle but non-significant deficits on formal neuropsychological testing and during IOR (i.e., moderate effect size). These effects may not have reached conventional levels of statistical significance secondary to low power. In

\section{Table 2. Regions Demonstrating Hypoactivation for Mild Traumatic Brain Injury Patients Relative to Healthy Controls}

\begin{tabular}{|c|c|c|c|c|c|c|}
\hline Region & Side & $B A s$ & $X$ & $Y$ & $Z$ & $\begin{array}{l}\text { Volume } \\
\quad(m L)\end{array}$ \\
\hline \multicolumn{7}{|l|}{ Parietal } \\
\hline $\begin{array}{l}\text { Posterior cingulate } \\
\text { gyrus }\end{array}$ & $\mathrm{M}$ & 23 & 0 & -19 & 27 & 1.173 \\
\hline \multicolumn{7}{|l|}{ Subcortical } \\
\hline $\begin{array}{l}\text { Thalamus and basal } \\
\text { ganglia }\end{array}$ & $\begin{array}{l}\mathrm{R} \\
\mathrm{L}\end{array}$ & & $\begin{array}{r}8 \\
-10\end{array}$ & $\begin{array}{l}-11 \\
-11\end{array}$ & $\begin{array}{l}2 \\
2\end{array}$ & $\begin{array}{l}3.432 \\
4.612\end{array}$ \\
\hline $\begin{array}{l}\text { Cerebellum } \\
\text { Lingual and culmen }\end{array}$ & $\mathrm{M}$ & & 0 & -38 & -8 & 1.429 \\
\hline
\end{tabular}

Side refers to the hemisphere showing activation (M, midline; $\mathrm{L}$, left; $\mathrm{R}$, right hemisphere). The Brodmann area (BA), the center of mass in Talairach coordinates (X, Y, and $\mathrm{Z})$, and volume in milliliter $(\mathrm{mL})$ are specified for each area of activation. contrast, functional results indicated that patients with mTBI demonstrated significantly decreased hemodynamic activation during the orienting task, with a spatial topography that was very similar to that seen in our previous study in an adult mTBI population (Mayer et al., 2009).

Although cognitive deficits in the domains of attention, memory, and processing speed, on traditional neuropsychological measures were not statistically significant, moderate effect sizes were noted, with HC showing better functioning than our pediatric mTBI patients. Furthermore, although no evidence of disengagement deficits were observed at the short SOA, a moderate effect size related to a group difference in IOR was observed during the auditory orienting task at the long SOA, with mTBI patients failing to exhibit the expected reversal in reaction times for invalid and valid cues. Previous work by others (Halterman et al., 2006) has suggested that attentional disengagement may be particularly affected following mTBI, although our current results did not support this hypothesis. This may be a result of the small sample size or the longer duration of time between measurements of attentional deficits in the current $(16.06 \pm 4.82$ mean days) versus the previous ( $37 \pm 11.5$ mean hours) study (Halterman et al., 2006). Finally, larger IOR effects were associated with better attention function in controls (as indexed by the attention composite score), but not in patients, suggesting a 


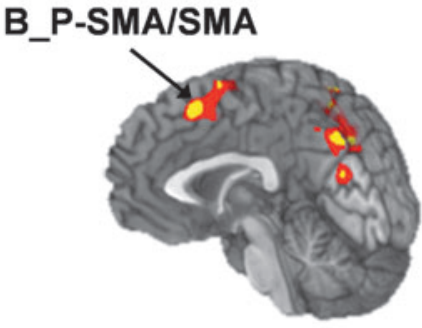

B_P-SMA/SMA

$X=-2$

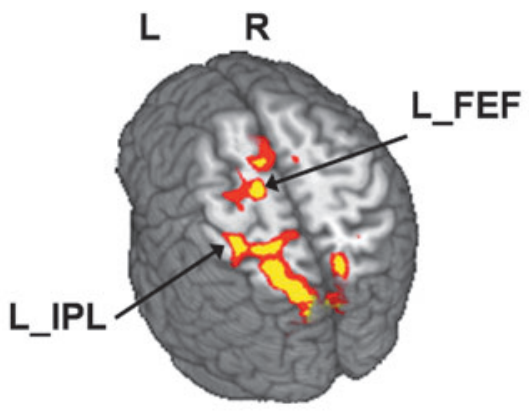

$Z=54$

$Z \geq 2.33$

$Z \geq 2.81$
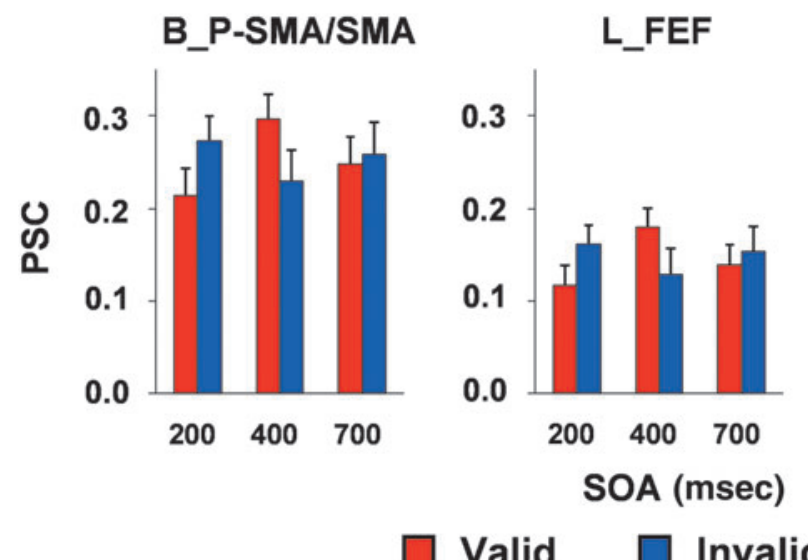

L_IPL

0.3

0.2

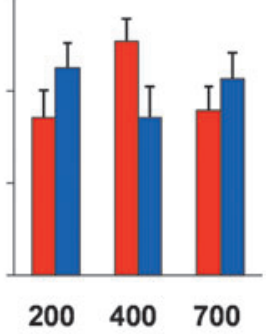

Valid $\square$ Invalid

FIG. 4. This figure presents the regions that exhibited a significant validity $\times \mathrm{SOA}$ interaction when mild traumatic brain injury (mTBI) and healthy controls (HC) were collapsed. The magnitudes of z-scores are represented by either red or yellow coloring. Locations of the sagittal $(X)$ and axial $(Z)$ slices are given according to the Talairach atlas (L, left; $R$, right). Percent signal change (PSC) values for the regions implicated in the interaction are presented for valid (red bars) and invalid (blue bars) trials at 200, 400, and $700 \mathrm{msec}$ SOA. The areas included the bilateral pre-supplementary/supplementary motor area (B_P-SMA/SMA), the near left frontal eye fields (L_FEF), and the left inferior parietal lobe (L_IPL). Error bars correspond to the standard error of the mean (SOA, stimulus onset asynchrony).

potential disruption in the relationship between the basic orienting function and the everyday cognitive functions measured with the neuropsychological tests following mTBI.

Our current results are consistent with those of previous studies that have reported subtle deficits in attention (Catroppa et al., 2007), memory (Babikian et al., 2011), and processing speed (Babikian et al., 2011), following pediatric mTBI.
However, other evidence suggests that the effects of mTBI on neurocognitive function in children are negligible during both the acute and chronic injury phases (Babikian and Asarnow, 2009; Satz et al., 1997). Given the greater variability in performance for pediatric samples, and the differences in cognitive functioning across relatively small age ranges, the quantitative assessment of neurobehavioral sequelae following pediatric

Table 3. Regions Implicated in the SOA by Validity Interaction

\begin{tabular}{|c|c|c|c|c|c|c|c|c|c|}
\hline \multirow[b]{2}{*}{ Region } & \multirow[b]{2}{*}{ Side } & \multirow[b]{2}{*}{ BAs } & \multirow[b]{2}{*}{$X$} & \multirow[b]{2}{*}{$Y$} & \multirow[b]{2}{*}{$Z$} & \multirow{2}{*}{$\begin{array}{c}\text { Volume } \\
(m L)\end{array}$} & \multicolumn{3}{|c|}{$S O A$} \\
\hline & & & & & & & $200 \mathrm{msec}$ & $400 \mathrm{msec}$ & $700 \mathrm{msec}$ \\
\hline \multicolumn{10}{|l|}{ Frontal } \\
\hline Pre-SMA/SMA/anterior cingulate & M & $6 / 8 / 24 / 32$ & -3 & 3 & 53 & 4.652 & $\mathrm{INV}>\mathrm{VAL}$ & $\mathrm{INV}<\mathrm{VAL}$ & n.s. \\
\hline Middle frontal and precentral gyrus & $\mathrm{L}$ & 6 & -18 & -12 & 58 & 3.206 & $\mathrm{INV}>\mathrm{VAL}$ & $\mathrm{INV}<\mathrm{VAL}$ & n.s. \\
\hline \multicolumn{10}{|l|}{ Parietal and occipital } \\
\hline Posterior parietal cortex & $\mathrm{L}$ & $2 / 3 / 4 / 5 / 7 / 40$ & -28 & -38 & 58 & 4.514 & $\mathrm{INV}>\mathrm{VAL}$ & $\mathrm{INV}<\mathrm{VAL}$ & n.s. \\
\hline Precuneus and cuneus & $\mathrm{R}$ & $7 / 19$ & 11 & -66 & 45 & 3.374 & $\mathrm{INV}>\mathrm{VAL}$ & $\mathrm{INV}<\mathrm{VAL}$ & n.s. \\
\hline & $\mathrm{L}$ & $5 / 7 / 18 / 19 / 31$ & -14 & -63 & 40 & 13.972 & $\mathrm{INV}>\mathrm{VAL}$ & $\mathrm{INV}<\mathrm{VAL}$ & n.s. \\
\hline
\end{tabular}

Side refers to the hemisphere showing activation ( $\mathrm{M}$, midline; $\mathrm{L}$, left; $\mathrm{R}$, right hemisphere). The Brodmann area (BA), the center of mass in Talairach coordinates ( $\mathrm{X}, \mathrm{Y}$, and $\mathrm{Z})$, and volume are specified for each area of activation.

SOA, stimulus onset asynchrony; SMA, supplementary motor area; INV, invalid; VAL, valid; n.s., not significant. 
mTBI is very challenging. Our inclusion of a well-defined mTBI cohort studied during a relatively homogeneous interval postinjury may have contributed to the higher effect size observed in the current study. In addition, controls were carefully matched for age and education, and were not statistically different on primary indicators of socioeconomic status (i.e., parental education), which likely controlled for the pre-injury risk factors (Ponsford et al., 1999). Thus, our careful selection of the control group may have also decreased variability.

Across both control and patient groups, our functional results showed the characteristic activation of the fronto-parietal attention network during attentional reorienting (Corbetta and Shulman, 2011). Specifically, increased activation within the frontal oculomotor sites and posterior parietal lobe was observed, associated with invalidly-cued compared to validlycued trials at $200 \mathrm{msec}$ SOA. In contrast, the functional activation for all these sites was reversed at $400 \mathrm{msec}$ SOA, and was approximately equivalent at $700 \mathrm{msec}$ SOA, for both validly-cued and invalidly-cued trials. These results are generally consistent with previous studies on bottom-up auditory orienting in adults (Mayer et al., 2007,2009), and provide additional evidence that the covert exogenous orienting network has matured during late childhood and adolescence (Brodeur and Enns, 1997; Rueda et al., 2004,; Waszak et al., 2010).

Our primary clinical observation was that patients with mTBI demonstrated hypoactivation within the bilateral posterior cingulate gyrus, thalamus, basal ganglia, midbrain nuclei, and cerebellum, relative to the control group. Moreover, levels of functional activation within these regions correctly classified mTBI from $\mathrm{HC}$ at $85.7 \%$ accuracy, suggesting that these objective imaging measures could potentially serve as a biomarker to evaluate/diagnose mTBI. The current pattern of results is similar to that of our previous study examining auditory orienting in adult patients with mTBI using the same task (Mayer et al., 2009), providing preliminary evidence of replication, and suggesting that similar neural networks are impaired during the involuntary shift of auditory attention following mTBI, regardless of age.

These regions displaying hypoactivation following mTBI have been shown to be recruited by healthy populations during various spatial attention tasks, and also produce spatial attention deficits across other neurological disorders. For example, the thalamus has been shown to be involved in spatial orienting in both children and adults (Posner and Rothbart, 2007; Salmi et al., 2007), and neuroimaging studies in healthy controls have reported cerebellar activation in various forms of spatial attention tasks in youth (ClementsStephens et al., 2009), and adults (Belin et al., 2002; Mayer et al., 2007; Salmi et al., 2007; Zatorre et al., 2002). Autistic children with cerebellar hypoplasia exhibit impaired attentional shifts (Harris et al., 1999), as do adult patients with cerebellar or basal ganglia pathology (Ravizza and Ivry, 2001). Finally, children with spina bifida meningomyelocele (SBM) with congenital dysmorphology of the midbrain showed a higher cost of attentional disengagement and a lack of IOR compared to either healthy controls or children with SBM with no midbrain dysmorphology (Dennis et al., 2005).

We had initially predicted that hemodynamic functioning within the fronto-parietal attentional network would be particularly affected by mTBI. One potential explanation for the observation of the altered hemodynamic response within subcortical, thalamic, and cerebellar regions, rather than higher-order cortical areas, may be the nature of shear stress forces following biomechanical injury. Specifically, Zhang and colleagues (2004) used a finite element head model to demonstrate that the midbrain and the thalamus experienced the highest shear stress following mTBI, and that the shear stress response of these regions predicted injury severity. Furthermore, a recent animal study has shown that a single controlled cortical impact injury, consistent with a mild injury to the left parietal cortex, resulted in metabolic and microstructural changes in the bilateral hippocampus and thalamus as early as $2 \mathrm{~h}$ post-injury (Xu et al., 2011). Diffusion kurtosis imaging was able to detect microstructural alterations in these subcortical areas, even during the post-acute injury stage (Zhuo et al., 2012). Therefore, it is possible that the initial biomechanical forces may particularly affect the metabolism and microstructure of the midbrain and thalamus, which in turn alters hemodynamic brain function.

Previous fMRI studies on pediatric mTBI have reported either no difference (Krivitzky et al., 2011), or hypoactivation (Talavage et al., 2010), during a visual n-back working memory task, or hyperactivation during an inhibitory control task (Krivitzky et al., 2011). As noted earlier, a potential explanation for the differences in brain activation patterns across different fMRI studies includes heterogeneity in time post-injury. Our current results are consistent with previous findings of hypoactivation during the semi-acute phase of injury (Talavage et al., 2010). In contrast, no difference was observed when data were collected with a heterogeneous time interval spanning the semi-acute to the post-acute phase (Krivitzky et al., 2011), comprising a range in which the majority of patients are expected to recover. These results underscore the important role of homogeneity in time postinjury in examining the neural mechanisms of cognitive disruption, and suggest that the semi-acute phase of injury may be a critical period to characterize the subtle alterations in brain activation following mTBI. An additional explanation for the current findings of hypoactivation versus previous findings of hyperactivation (Krivitzky et al., 2011) is that the bottom-up orienting task is likely to be more consistent with a lower cognitive load, which has been shown to result in hypoactivation in adult mTBI patients (McAllister et al., 1999,2001).

Although rodent models suggest that molecular responses associated with growth, maturation, and metabolism may play a particularly important role in developmental TBI (Babikian et al., 2010), there are a variety of different physiological factors that could have contributed to the observed hypoactivation of the hemodynamic response. The blood-oxygen-level-dependent (BOLD) signal is an indirect measure of neuronal functioning, and its basic signal properties depend on cerebral blood flow, blood volume, and the ratio of deoxyhemoglobin to oxyhemoglobin (Logothetis, 2008). In addition, the neurometabolic cascade initiated by mild head injuries includes abrupt neuronal depolarization, the release of excitatory neurotransmitters, the disruption of ionic balance, changes in glucose metabolism, altered cerebral blood flow, and impaired axonal function (Barkhoudarian et al., 2011). Secondary injury symptoms include ischemia, hypotension, cerebral hypoxia, cerebral edema, changes in blood flow to the brain, and raised intracranial pressure (Scalea, 2005). Finally, damage to white matter tracts can also affect neuronal transmission, and alterations in fractional anisotropy have also been observed a few days post-injury in adolescents with mTBI (Wilde et al., 2008). 
There are several limitations of the present study. First, our modest sample size may have obscured important effects of mTBI on behavioral and neuropsychological variables, as moderate to large effect sizes were observed for group differences for both types of measures. Second, we did not match strictly for gender and observed a trend level difference in gender composition across groups. Thus the differential rate of development between pre-pubescent and pubescent males and females may contribute to the functional abnormalities observed in the mTBI patients. However, the sex-specific differences in brain activation typically favor a greater activation in the task-related regions in males compared to females in various attention tasks (Clements-Stephens et al., 2009; Tomasi et al., 2008). Thus more males in the mTBI group may make the finding of hypoactivation in the mTBI group more compelling. Third, we used healthy non-injured participants as the control group instead of participants with other injuries not involving the head (e.g., orthopedic injuries), which may prevent differentiating whether the altered neural activation is unique to mTBI, or is non-specific following any type of trauma (Babikian et al., 2011).

Finally, it is worth noting that the current findings represent neural activation at only a single point in time during the acute recovery phase ( $<3$ weeks). They do not provide information about the chronic changes in brain activation levels, nor do they shed light on the process of neural recovery over time. Longitudinal studies with larger sample sizes are needed to elucidate how alterations of brain activation during spatial attention at different recovery phases evolves over time. This information may provide a sensitive marker to the course of recovery that may help in measuring effects of intervention or guide the management of mTBI.

In conclusion, our current results provide evidence that pediatric patients with mTBI may experience hemodynamic alterations in neural circuitry supporting spatial orienting during the semi-acute injury phase. These objective neuroimaging findings could serve as a biomarker for the subtle injury caused by mTBI, and thus may provide important data affecting both diagnosis and the course of recovery. Such data could help guide clinicians in the management of mTBI, for example, in monitoring patient responses to interventions, or in revealing when hemodynamic abnormalities have subsided and the risk of a significant secondary injury response may be reduced. It is critical to specifically examine pediatric patients, as the semi-acute injury response and recovery trajectories following mTBI are likely to be different for the immature and mature brain (Suskauer and Huisman, 2009). For example, both animal (Bayly et al., 2006; Huh et al., 2008) and human (Hessen et al., 2007) studies have shown that the developing brain may be more susceptible than the developed brain to mild diffuse brain injury (Adelson and Kochanek, 1998; Levin, 2003). Finally, our current results also demonstrate that fMRI is more sensitive to the effects of mTBI than behavioral, neuropsychological, and traditional MRI measures, and they underscore the promise of fMRI for elucidating the potential neural substrates of subtle cognitive deficits associated with this condition.

\section{Acknowledgments}

The first author was supported by The Graduate Dean's Dissertation Fellowship sponsored by the University of New
Mexico and The Benjamin Franklin Haught Scholarship sponsored by the Department of Psychology, University of New Mexico. This research was supported by grants from The Mind Research Network [DOE Grant No. DE-FG0299ER62764] to A.R.M. Special thanks to Diana South, George Malloy, Cathy Smith, Terri Teshiba, Flannery Merideth, and Jim Youngblood for assistance with data collection and/or data entry, to Jesse Rael, M.D. for review of anatomical images, and to Vince Clark and John Phillips for serving on the dissertation committee.

\section{Author Disclosure Statement}

No competing financial interests exist.

\section{References}

Adelson, P.D., and Kochanek, P.M. (1998). Head injury in children. J. Child Neurol. 13, 2-15.

Allen, D.N., Leany, B.D., Thaler, N.S., Cross, C., Sutton, G.P., and Mayfield, J. (2010). Memory and attention profiles in pediatric traumatic brain injury. Arch. Clin. Neuropsychol. 25, 618-633.

Anderson, V., Catroppa, C., Morse, S., Haritou, F., and Rosenfeld, J. (2001). Outcome from mild head injury in young children: a prospective study. J. Clin. Exp. Neuropsychol. 23, 705-717.

Anderson, V., Catroppa, C., Morse, S., Haritou, F., and Rosenfeld, J. (2005). Attentional and processing skills following traumatic brain injury in early childhood. Brain Inj. 19, 699-710.

Arrington, C.M., Carr, T.H., Mayer, A.R., and Rao, S.M. (2000). Neural mechanisms of visual attention: object-based selection of a region in space. J. Cogn. Neurosci. 12 (Suppl. 2), 106-117.

Babikian, T., and Asarnow, R. (2009). Neurocognitive outcomes and recovery after pediatric TBI: meta-analytic review of the literature. Neuropsychology 23, 283-296.

Babikian, T., Prins, M.L., Cai, Y., Barkhoudarian, G., Hartonian, I., Hovda, D.A., and Giza, C.C. (2010). Molecular and physiological responses to juvenile traumatic brain injury: focus on growth and metabolism. Dev. Neurosci. 32, 431-441.

Babikian, T., Satz, P., Zaucha, K., Light, R., Lewis, R.S., and Asarnow, R.F. (2011). The UCLA longitudinal study of neurocognitive outcomes following mild pediatric traumatic brain injury. J. Int. Neuropsychol. Soc. 17, 886-895.

Barkhoudarian, G., Hovda, D.A., and Giza, C.C. (2011). The molecular pathophysiology of concussive brain injury. Clin. Sports Med. 30, 33-48, vii-iii.

Bayly, P.V., Dikranian, K.T., Black, E.E., Young, C., Qin, Y.Q., Labruyere, J., and Olney, J.W. (2006). Spatiotemporal evolution of apoptotic neurodegeneration following traumatic injury to the developing rat brain. Brain Res. 1107, 70-81.

Belanger, H.G., Vanderploeg, R.D., Curtiss, G., and Warden, D.L. (2007). Recent neuroimaging techniques in mild traumatic brain injury. J. Neuropsychiatry Clin. Neurosci. 19, 5-20.

Belin, P., McAdams, S., Thivard, L., Smith, B., Savel, S., Zilbovicius, M., Samson, S., and Samson, Y. (2002). The neuroanatomical substrate of sound duration discrimination. Neuropsychologia 40, 1956-1964.

Brodeur, D.A., and Enns, J.T. (1997). Covert visual orienting across the lifespan. Can. J. Exp. Psychol. 51, 20-35.

Burock, M.A., Buckner, R.L., Woldorff, M.G., Rosen, B.R., and Dale, A.M. (1998). Randomized event-related experimental designs allow for extremely rapid presentation rates using functional MRI. Neuroreport 9, 3735-3739. 
Catale, C., Marique, P., Closset, A., and Meulemans, T. (2009). Attentional and executive functioning following mild traumatic brain injury in children using the Test for Attentional Performance (TAP) battery. J. Clin. Exp. Neuropsychol. 31, 331-338.

Catroppa, C., and Anderson, V. (1999a). Attentional skills in the acute phase following pediatric traumatic brain injury. Child Neuropsychol. 5, 251-264.

Catroppa, C., and Anderson, V. (2003). Children's attentional skills 2 years post-traumatic brain injury. Dev. Neuropsychol. 23, 359-373.

Catroppa, C., and Anderson, V. (2005). A prospective study of the recovery of attention from acute to 2 years following pediatric traumatic brain injury. J. Int. Neuropsychol. Soc. 11, 84-98.

Catroppa, C., Anderson, V., Godfrey, C., and Rosenfeld, J.V. (2011). Attentional skills 10 years post-paediatric traumatic brain injury (TBI). Brain Inj. 25, 858-869.

Catroppa, C., Anderson, V., and Stargatt, R. (1999b). A prospective analysis of the recovery of attention following pediatric head injury. J. Int. Neuropsychol. Soc. 5, 48-57.

Catroppa, C., Anderson, V.A., Morse, S.A., Haritou, F., and Rosenfeld, J.V. (2007). Children's attentional skills 5 years post-TBI. J. Pediatr. Psychol. 32, 354-369.

Cazalis, F., Babikian, T., Giza, C., Copeland, S., Hovda, D., and Asarnow, R.F. (2011). Pivotal role of anterior cingulate cortex in working memory after traumatic brain injury in youth. Front. Neurol. 1, 158.

Centers for Disease Control and Prevention. (2003). Report to Congress on mild traumatic brain injury in the United States: steps to prevent a serious public health problem. National Center for Injury Prevention and Control: Atlanta, pps. 1-5.

Cicerone, K., Levin, H., Malec, J., Stuss, D., and Whyte, J. (2006). Cognitive rehabilitation interventions for executive function: moving from bench to bedside in patients with traumatic brain injury. J. Cogn. Neurosci. 18, 1212-1222.

Clements-Stephens, A.M., Rimrodt, S.L., and Cutting, L.E. (2009). Developmental sex differences in basic visuospatial processing: differences in strategy use? Neurosci. Lett. 449, 155-160.

Corbetta, M., and Shulman, G.L. (2011). Spatial neglect and attention networks. Annu. Rev. Neurosci. 34, 569-599.

Cox, R.W. (1996). AFNI: software for analysis and visualization of functional magnetic resonance neuroimages. Comput. Biomed. Res. 29, 162-173.

Daneshvar, D.H., Riley, D.O., Nowinski, C.J., McKee, A.C., Stern, R.A., and Cantu, R.C. (2011). Long-term consequences: effects on normal development profile after concussion. Phys. Med. Rehabil. Clin. N. Am. 22, 683-700, ix.

Dennis, M., Edelstein, K., Copeland, K., Frederick, J., Francis, D.J., Hetherington, R., Blaser, S.E., Kramer, L.A., Drake, J.M., Brandt, M.E., and Fletcher, J.M. (2005). Covert orienting to exogenous and endogenous cues in children with spina bifida. Neuropsychologia 43, 976-987.

Drew, A.S., Langan, J., Halterman, C., Osternig, L.R., Chou, L.S., and van Donkelaar, P. (2007). Attentional disengagement dysfunction following mTBI assessed with the gap saccade task. Neurosci. Lett. 417, 61-65.

Faul, M., Xu, L., Wald, M.M., and Coronado, V.G. (2010). Traumatic brain injury in the United States: emergency department visits, hospitalizations, and deaths 2002-2006. Centers for Disease Control and Prevention, National Center for Injury Prevention and Control: Atlanta.

Fay, G.C., Jaffe, K.M., Polissar, N.L., Liao, S., Rivara, J.B., and Martin, K.M. (1994). Outcome of pediatric traumatic brain injury at three years: a cohort study. Arch. Phys. Med. Rehabil. 75, 733-741.

Fay, T.B., Yeates, K.O., Taylor, H.G., Bangert, B., Dietrich, A., Nuss, K.E., Rusin, J., and Wright, M. (2010). Cognitive reserve as a moderator of postconcussive symptoms in children with complicated and uncomplicated mild traumatic brain injury. J. Int. Neuropsychol. Soc. 16, 94-105.

Giedd, J.N., Blumenthal, J., Jeffries, N.O., Castellanos, F.X., Liu, H., Zijdenbos, A., Paus, T., Evans, A.C., and Rapoport, J.L. (1999). Brain development during childhood and adolescence: a longitudinal MRI study. Nat. Neurosci. 2, 861-863.

Ginstfeldt, T., and Emanuelson, I. (2010). An overview of attention deficits after paediatric traumatic brain injury. Brain Inj. 24, 1123-1134.

Glover, G.H. (1999). Deconvolution of impulse response in event-related BOLD fMRI. Neuroimage 9, 416-429.

Goldberg, M.C., Maurer, D., and Lewis, T.L. (2001). Developmental changes in attention: the effect of endogenous cueing and of distractors. Dev. Sci. 4, 209-219.

Halterman, C.I., Langan, J., Drew, A., Rodriguez, E., Osternig, L.R., Chou, L.S., and van Donkelaar, P. (2006). Tracking the recovery of visuospatial attention deficits in mild traumatic brain injury. Brain 129, 747-753.

Hamilton, N.A., and Keller, M.S. (2010). Mild traumatic brain injury in children. Semin. Pediatr. Surg. 19, 271-278.

Harris, N.S., Courchesne, E., Townsend, J., Carper, R.A., and Lord, C. (1999). Neuroanatomic contributions to slowed orienting of attention in children with autism. Brain Res. Cogn. Brain Res. 8, 61-71.

Hessen, E., Nestvold, K., and Anderson, V. (2007). Neuropsychological function 23 years after mild traumatic brain injury: a comparison of outcome after paediatric and adult head injuries. Brain Inj. 21, 963-979.

Hughes, D.G., Jackson, A., Mason, D.L., Berry, E., Hollis, S., and Yates, D.W. (2004). Abnormalities on magnetic resonance imaging seen acutely following mild traumatic brain injury: correlation with neuropsychological tests and delayed recovery. Neuroradiology 46, 550-558.

Huh, J.W., Widing, A.G., and Raghupathi, R. (2008). Midline brain injury in the immature rat induces sustained cognitive deficits, bihemispheric axonal injury and neurodegeneration. Exp. Neurol. 213, 84-92.

Jaffe, K.M., Fay, G.C., Polissar, N.L., Martin, K.M., Shurtleff, H., Rivara, J.B., and Winn, H.R. (1992). Severity of pediatric traumatic brain injury and early neurobehavioral outcome: a cohort study. Arch. Phys. Med. Rehabil. 73, 540-547.

Karunanayaka, P.R., Holland, S.K., Yuan, W., Altaye, M., Jones, B.V., Michaud, L.J., Walz, N.C., and Wade, S.L. (2007). Neural substrate differences in language networks and associated language-related behavioral impairments in children with TBI: a preliminary fMRI investigation. NeuroRehabilitation 22, 355-369.

Kaufmann, P.M., Fletcher, J.M., Levin, H.S., Miner, M.E., and Ewing-Cobbs, L. (1993). Attentional disturbance after pediatric closed head injury. J. Child Neurol. 8, 348-353.

Keenan, H.T., and Bratton, S.L. (2006). Epidemiology and outcomes of pediatric traumatic brain injury. Dev. Neurosci. 28, 256-263.

Kirkwood, M.W., Yeates, K.O., Taylor, H.G., Randolph, C., McCrea, M., and Anderson, V.A. (2008). Management of pediatric mild traumatic brain injury: a neuropsychological review from injury through recovery. Clin. Neuropsychol. 22, 769-800.

Klonoff, H., Clark, C., and Klonoff, P.S. (1993). Long-term outcome of head injuries: a 23 year follow up study of children 
with head injuries. J. Neurol. Neurosurg. Psychiatry 56, 410415.

Kramer, M.E., Chiu, C.Y., Shear, P.K., and Wade, S.L. (2009). Neural correlates of verbal associative memory and mnemonic strategy use following childhood traumatic brain injury. J. Pediatr. Rehabil. Med. 2, 255-271.

Kramer, M.E., Chiu, C.Y., Walz, N.C., Holland, S.K., Yuan, W., Karunanayaka, P., and Wade, S.L. (2008). Long-term neural processing of attention following early childhood traumatic brain injury: fMRI and neurobehavioral outcomes. J. Int. Neuropsychol. Soc. 14, 424-435.

Krivitzky, L.S., Roebuck-Spencer, T.M., Roth, R.M., Blackstone, K., Johnson, C.P., and Gioia, G. (2011). Functional magnetic resonance imaging of working memory and response inhibition in children with mild traumatic brain injury. J. Int. Neuropsychol. Soc. 17, 1143-1152.

Lepsien, J., and Pollmann, S. (2002). Covert reorienting and inhibition of return: an event-related fMRI study. J. Cogn. Neurosci. 14, 127-144.

Levin, H.S. (2003). Neuroplasticity following non-penetrating traumatic brain injury. Brain Inj. 17, 665-674.

Logothetis, N.K. (2008). What we can do and what we cannot do with fMRI. Nature 453, 869-878.

Lovell, M.R., Pardini, J.E., Welling, J., Collins, M.W., Bakal, J., Lazar, N., Roush, R., Eddy, W.F., and Becker, J.T. (2007). Functional brain abnormalities are related to clinical recovery and time to return-to-play in athletes. Neurosurgery 61, 352359.

Mayer, A.R., Dorflinger, J.M., Rao, S.M., and Seidenberg, M. (2004). Neural networks underlying endogenous and exogenous visual-spatial orienting. Neuroimage 23, 534-541.

Mayer, A.R., Harrington, D.L., Stephen, J., Adair, J.C., and Lee, R.R. (2007). An event-related fMRI study of exogenous facilitation and inhibition of return in the auditory modality. J. Cogn. Neurosci. 19, 455-467.

Mayer, A.R., Mannell, M.V., Ling, J., Elgie, R., Gasparovic, C., Phillips, J.P., Doezema, D., and Yeo, R.A. (2009). Auditory orienting and inhibition of return in mild traumatic brain injury: a FMRI study. Hum. Brain Mapp. 30, 4152-4166.

McAllister, T.W., Flashman, L.A., McDonald, B.C., and Saykin, A.J. (2006). Mechanisms of working memory dysfunction after mild and moderate TBI: evidence from functional MRI and neurogenetics. J. Neurotrauma 23, 1450-1467.

McAllister, T.W., Saykin, A.J., Flashman, L.A., Sparling, M.B., Johnson, S.C., Guerin, S.J., Mamourian, A.C., Weaver, J.B., and Yanofsky, N. (1999). Brain activation during working memory 1 month after mild traumatic brain injury: a functional MRI study. Neurology 53, 1300-1308.

McAllister, T.W., Sparling, M.B., Flashman, L.A., Guerin, S.J., Mamourian, A.C., and Saykin, A.J. (2001). Differential working memory load effects after mild traumatic brain injury. Neuroimage 14, 1004-1012.

McKinlay, A., Dalrymple-Alford, J.C., Horwood, L.J., and Fergusson, D.M. (2002). Long term psychosocial outcomes after mild head injury in early childhood. J. Neurol. Neurosurg. Psychiatry 73, 281-288.

McKinlay, A., Grace, R., Horwood, J., Fergusson, D., and MacFarlane, M. (2009). Adolescent psychiatric symptoms following preschool childhood mild traumatic brain injury: evidence from a birth cohort. J. Head Trauma Rehabil. 24, 221-227.

McKinlay, A., Grace, R.C., Horwood, L.J., Fergusson, D.M., and MacFarlane, M.R. (2010). Long-term behavioural outcomes of pre-school mild traumatic brain injury. Child. Care. Health Dev. 36, 22-30.
Newsome, M.R., Scheibel, R.S., Hunter, J.V., Wang, Z.J., Chu, Z., Li, X., and Levin, H.S. (2007). Brain activation during working memory after traumatic brain injury in children. Neurocase 13, 16-24.

Newsome, M.R., Steinberg, J.L., Scheibel, R.S., Troyanskaya, M., Chu, Z., Hanten, G., Lu, H., Lane, S., Lin, X., Hunter, J.V., Vasquez, C., Zientz, J., Li, X., Wilde, E.A., and Levin, H.S. (2008). Effects of traumatic brain injury on working memoryrelated brain activation in adolescents. Neuropsychology 22, 419-425.

Ponsford, J., Willmott, C., Rothwell, A., Cameron, P., Ayton, G., Nelms, R., Curran, C., and Ng, K.T. (1999). Cognitive and behavioral outcome following mild traumatic head injury in children. J Head Trauma Rehabil. 14, 360-372.

Posner, M.I., and Rothbart, M.K. (2007). Learning to look, in: Educating the Human Brain. American Psychological Association: Washington, pps. 62-68.

Ravizza, S.M., and Ivry, R.B. (2001). Comparison of the basal ganglia and cerebellum in shifting attention. J. Cogn. Neurosci. 13, 285-297.

Reynolds, C.R., and Kamphaus, R.W. (2004). BASC-2: Behavior Assessment System for Children, Second Edition. American Guidance Service Circle Pines.

Rueda, M.R., Fan, J., McCandliss, B.D., Halparin, J.D., Gruber, D.B., Lercari, L.P., and Posner, M.I. (2004). Development of attentional networks in childhood. Neuropsychologia 42, 1029-1040.

Salmi, J., Rinne, T., Degerman, A., Salonen, O., and Alho, K. (2007). Orienting and maintenance of spatial attention in audition and vision: multimodal and modality-specific brain activations. Brain Struct. Funct. 212, 181-194.

Satz, P., Zaucha, K., McCleary, C., Light, R., Asarnow, R., and Becker, D. (1997). Mild head injury in children and adolescents: a review of studies (1970-1995). Psychol. Bull. 122, 107131.

Scalea, T.M. (2005). Does it matter how head injured patients are resuscitated? in: Neurotrauma: Evidence-Based Answer to Common Questions. A.B. Valadka, and B.T. Andrew (eds). Thieme: New York, pps. 3-5.

Slobounov, S.M., Zhang, K., Pennell, D., Ray, W., Johnson, B., and Sebastianelli, W. (2010). Functional abnormalities in normally appearing athletes following mild traumatic brain injury: a functional MRI study. Exp. Brain Res. 202, 341-354.

Smits, M., Dippel, D.W., Houston, G.C., Wielopolski, P.A., Koudstaal, P.J., Hunink, M.G., and van der Lugt, A. (2009). Postconcussion syndrome after minor head injury: brain activation of working memory and attention. Hum. Brain Mapp. 30, 2789-2803.

Sowell, E.R., Trauner, D.A., Gamst, A., and Jernigan, T.L. (2002). Development of cortical and subcortical brain structures in childhood and adolescence: a structural MRI study. Dev. Med. Child Neurol. 44, 4-16.

Sterr, A., Herron, K.A., Hayward, C., and Montaldi, D. (2006). Are mild head injuries as mild as we think? Neurobehavioral concomitants of chronic post-concussion syndrome. BMC Neurol. 6, 7.

Suskauer, S.J., and Huisman, T.A. (2009). Neuroimaging in pediatric traumatic brain injury: current and future predictors of functional outcome. Dev. Disabil. Res. Rev. 15, 117-123.

Talairach, J., and Tournoux, P. (1988). Co-Planar Stereotaxic Atlas of the Human Brain: 3-Dimensional Proportional System-An Approach to Cerebral Imaging. Thieme: New York.

Talavage, T.M., Nauman, E., Breedlove, E.L., Yoruk, U., Dye, A.E., Morigaki, K., Feuer, H., and Leverenz, L.J. (2010). 
Functionally-detected cognitive impairment in high school football players without clinically-diagnosed concussion. J. Neurotrauma [Epub ahead of print].

Thiel, C.M., Zilles, K., and Fink, G.R. (2004). Cerebral correlates of alerting, orienting and reorienting of visuospatial attention: an event-related fMRI study. Neuroimage 21, 318-328.

Tlustos, S.J., Chiu, C.Y., Walz, N.C., Holland, S.K., Bernard, L., and Wade, S.L. (2011). Neural correlates of interference control in adolescents with traumatic brain injury: functional magnetic resonance imaging study of the counting Stroop task. J. Int. Neuropsychol. Soc. 17, 181-189.

Tomasi, D., Chang, L., Caparelli, E.C., and Ernst, T. (2008). Sex differences in sensory gating of the thalamus during auditory interference of visual attention tasks. Neuroscience 151, 10061015.

Waszak, F., Li, S.C., and Hommel, B. (2010). The development of attentional networks: cross-sectional findings from a life span sample. Dev. Psychol. 46, 337-349.

Wilde, E.A., McCauley, S.R., Hunter, J.V., Bigler, E.D., Chu, Z., Wang, Z.J., Hanten, G.R., Troyanskaya, M., Yallampalli, R., Li, X., Chia, J., and Levin, H.S. (2008). Diffusion tensor imaging of acute mild traumatic brain injury in adolescents. Neurology 70, 948-955.

Wilde, E.A., Newsome, M.R., Bigler, E.D., Pertab, J., Merkley, T.L., Hanten, G., Scheibel, R.S., Li, X., Chu, Z., Yallampalli, R., Hunter, J.V., and Levin, H.S. (2011). Brain imaging correlates of verbal working memory in children following traumatic brain injury. Int. J. Psychophysiol. 82, 86-96.

Witt, S.T., Lovejoy, D.W., Pearlson, G.D., and Stevens, M.C. (2010). Decreased prefrontal cortex activity in mild traumatic brain injury during performance of an auditory oddball task. Brain Imaging Behav. 4, 232-247.

Xu, S., Zhuo, J., Racz, J., Shi, D., Roys, S., Fiskum, G., and Gullapalli, R. (2011). Early microstructural and metabolic changes following controlled cortical impact injury in rat: a magnetic resonance imaging and spectroscopy study. J. Neurotrauma 28, 2091-2102.

Yeates, K.O., Taylor, H.G., Rusin, J., Bangert, B., Dietrich, A., Nuss, K., Wright, M., Nagin, D.S., and Jones, B.L. (2009). Longitudinal trajectories of postconcussive symptoms in children with mild traumatic brain injuries and their relationship to acute clinical status. Pediatrics 123, 735-743.

Zatorre, R.J., Bouffard, M., Ahad, P., and Belin, P. (2002). Where is 'where' in the human auditory cortex? Nat. Neurosci. 5, 905-909.

Zhang, L., Yang, K.H., and King, A.I. (2004). A proposed injury threshold for mild traumatic brain injury. J. Biomech. Eng. 126, 226-236.

Zhuo, J., Xu, S., Proctor, J.L., Mullins, R.J., Simon, J.Z., Fiskum, G., and Gullapalli, R.P. (2012). Diffusion kurtosis as an in vivo imaging marker for reactive astrogliosis in traumatic brain injury. Neuroimage 59, 467-477.

Address correspondence to: Andrew R. Mayer, Ph.D. The Mind Research Network Pete $\mathcal{E}$ Nancy Domenici Hall 1101 Yale Boulevard, N.E. Albuquerque, NM 87106

E-mail: amayer@mrn.org 